\title{
A ARTE MODERNA COMO HISTORICAMENTE-SUBLIME UM COMENTÁRIO SOBRE O CONCEITO DE SUBLIME NA TEORIA ESTÉTICA DE TH. ADORNO
}

Verlaine Freitas* verlainefreitas@gmail.com

RESUMO O objetivo do texto é propor uma interpretação do conceito de sublime na Teoria estética de Theodor Adorno, partindo do confronto com leituras significativas de outros comentadores, de modo a fornecer uma concepção que associe o movimento de transcendência e alteridade da forma estética à dinâmica histórico-processual das obras.

Palavras-chave Theodor Adorno, teoria estética, sublime, historicidade.

ABSTRACT The objective of this paper is to propose an interpretation of the concept of sublime in the Aesthetic Theory of Theodor Adorno, starting with the confrontation with meaningful readings of other commentators, in order to provide a conception that links the movement of transcendence and otherness of the aesthetic form to the process-historical dynamics of the works.

Keywords Theodor Adorno, aesthetic theory, sublime, historicity. 
Junto com o declínio de princípios de unificação para as obras de arte a partir da vanguarda do início do século XX, como a figuração nas artes plásticas, o centro tonal na música e o narrador onisciente na literatura, assistiu-se à presença cada vez mais forte de elementos refratários ao que se pode chamar de um bom gosto sedimentado socialmente, de modo que o feio, o repugnante, o nonsense, passaram a fazer parte indissolúvel da estética moderna. Em virtude disso, a categoria do belo tornou-se especialmente fraca ou no mínimo bastante problemática como princípio não apenas descritivo quanto também hermenêutico. Em seu lugar, o sublime experimentou uma valorização deveras significativa, sendo tema de diversos tratados, congressos e artigos. Em sua estética, Theodor Adorno também fez um uso relevante desta categoria, embora não tenha lhe conferido uma definição mais específica (como, de resto, ocorre amiúde em sua filosofia, avessa a definições prévias para o discurso filosófico). Diante de uma divergência que nos parece um tanto surpreendente nas leituras sobre o significado deste conceito na obra adorniana, pretendemos fornecer uma concepção de sublime que, embora não explicitada como tal pelo filósofo, se nutre de vários de seus conceitos, almejando uma resolução interpretativa que ultrapasse as deficiências que vemos na tradição de comentários. ${ }^{1}$

Nosso percurso se inicia com uma apresentação crítica de três autores que nos parecem mais significativos neste panorama: Albrecht Wellmer, Jan Rosiek e Wolfgang Welsch. (Embora tal discussão ocupe boa parte de nosso texto, consideramo-la necessária, pois fornece suporte a nossa proposta hermenêutica, além de esclarecer de forma válida aspectos significativos do conceito de sublime na Teoria estética.) Em seguida, falaremos sobre o caráter histórico-temporal da obra de arte, de modo a fornecer elementos que sustentem nossa tese interpretativa, colocada na parte final. Nesta última, argumentaremos a favor de nosso conceito de sublime em íntima vinculação ao caráter histórico/processual da obra de arte, momento em que a dimensão de alteridade/transcendência se liga às tensões da configuração das obras, tanto em sua dimensão monadológica, quanto em sua inserção na história.

\section{I}

Diversos comentadores de Adorno propuseram uma análise do conceito de sublime na Teoria estética. ${ }^{2}$ Dentre eles, três merecem destaque por sua

1 Este texto é resultado de uma reelaboração de parte do capítulo IV de nossa tese de doutorado, Para uma dialética da alteridade. A constituição do sujeito, da razão e do tempo em Theodor Adorno.

2 Veja-se, por exemplo, Martin Seel, "Dialektik des Erhabenen. Kommentare zur 'ästhetischen Barberei heute"; Wolfgang Welsch, "Adornos Ästhetik: eine implizite Ästhetik des Erhabenen"; Albrecht Wellmer, 
originalidade, pois não apenas se dedicaram a apresentar e "explicar" o pensamento adorniano, mas propor uma interpretação, de alguma forma, mais independente: W. Welsch, A. Wellmer e Jan Rosiek. Embora seja a mais antiga, a concepção de Welsch é a que mais se aproxima de nossa opção de considerar o sublime em sua qualidade de experiência estética propriamente dita, motivo pelo qual será objeto de uma análise mais detalhada.

Albrecht Wellmer, ao comentar o conceito de sublime na Teoria estética, vincula as ideias de Adorno ao conceito de comunicação, concebido à luz da racionalidade comunicativa de Habermas. Para o comentador, o sublime adorniano poderia ser tomado propriamente como um momento em que as relações não resolvidas entre o absurdo e o sentido que se estabelece linguisticamente adquirem a oportunidade de comunicação através da arte: “comunicação do incomunicável, representação do irrepresentável são características da arte, através das quais esta pode lidar com todos os possíveis aspectos de nossa experiência do mundo"3. Trata-se de substituir o pessimismo sombrio que o autor vê nas filosofias de Nietzsche e de Adorno pelo otimismo da concepção política habermasiana. Apesar de essa concepção mostrar-se em grande parte fiel ao texto adorniano e ser muito bem construída, possui uma estrutura argumentativa que a torna problemática como interpretação do texto de Adorno, uma vez que os conceitos de falta de sentido e de comunicação que a sustentam derivam do paradigma filosófico da racionalidade comunicativa de

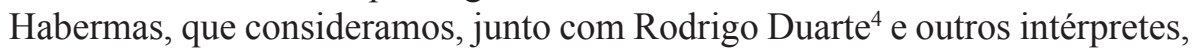
como muito distante da concepção filosófica adorniana. Embora tal viés de abordagem forneça certa originalidade na leitura sobre o sublime em Adorno, encaminha a problemática mais decisiva para "soluções" conceituais que abandonam, em grande medida, fundamentos nucleares da estética de Adorno.

Outro comentador, Rosiek, produziu um verdadeiro tratado sobre o conceito de sublime, tanto no que concerne a Heidegger, quanto a Adorno. De todas as abordagens sobre o sublime na Teoria estética, é a mais abrangente e extensa. Apesar dessa proeminência, sua leitura está seriamente comprometida pelo conceito geral de sublime que serve de baliza para sua obra, que é o da "tradução religiosa-literária do metafísico"s. O autor procura, em vários momentos, ressaltar as ligações do sublime com a experiência religiosa e

"Adorno, Modernity, and the Sublime"; María Isabel Peña Aguado, "Theodor W. Adorno. Die Transformation des Erhabenen in der Ästhetischen Theorie"; Jan Rosiek. Mantaining the sublime. Cf. a bibliografia ao final para detalhes quanto às referências bibliográficas.

4 Cf., por exemplo, Rodrigo Duarte, "Expressão como fundamentação".

5 Jan Rosiek, op. cit., pp.3 ss. 
teológica, fazendo com que aquilo que é concebido como o totalmente outro seja absorvido pela experiência do sagrado. Trata-se de perceber a sublimidade como expressão estética do contato com a transcendência religiosa. Com base nessa opção geral, ao tratar do sublime em Adorno, Rosiek subjuga todos os elementos de ruptura da subjetividade - típicos da experiência-limite do sublime - à ideia geral de um contato (positivo) com a transcendência.

Falando sobre o sublime como uma promessa de um outro em relação ao atual estado de coisas, Rosiek diz que

Adorno reitera que a própria forma da obra de arte é uma articulação da promessa que abre para o outro; mas, mais que isso, a promessa é vista como uma garantia atual de sua possibilidade, embora não ainda como uma garantia de sua existência atual. A articulação dessa pequena esperança não é típica do discurso de Adorno sobre promessas; ele é mais apto a enfatizar as rupturas do que sua realização potencial. ${ }^{6}$

Abordando a ligação entre a obra de arte e a transcendência, diz o comentador:

A transcendência sugerida pela obra de arte é sua "fala" ou "escrita", mas fala e escrita que, deve-se observar, são "sem significado" - ou, para ser mais preciso, e, de fato, faz muita diferença - "com um significado truncado ou velado" (ÄT 122/967). $\mathrm{O}$ adjetivo "velado", zugehängter, indica uma cobertura por uma cortina de teatro e a ocultação da cena da transcendência mencionada anteriormente. (...) no que se segue, tentarei levantar a cortina. ${ }^{8}$

A primeira passagem mostra o reconhecimento por parte de Rosiek de que Adorno está mais próximo da negação de uma efetividade da promessa da alteridade transcendente do que de sua afirmação, e insiste, apesar disso, em ressaltar o aspecto afirmativo em sua análise. A segunda passagem indica como o comentador opta, explicitamente, por romper com o paradigma adorniano de manutenção da ideia de que o significado transcendente da arte permanece velado. A grande questão é que essas duas opções interpretativas contrariam de forma significativa o cerne da filosofia de Adorno. Embora todo o texto de Rosiek seja muito bem elaborado, todo seu vigor interpretativo foi dirigido em prol de uma concepção parcial e, principalmente, tendenciosa. Ele pretende interpretar a ontologia fundamental de Heidegger e a dialética negativa de Adorno a partir de uma mesma concepção religiosa do sublime, o que nos parece uma abordagem realmente imprópria.

6 Jan Rosiek, op. cit., p.383.

7 A Teoria estética de Adorno será referida no texto como ÄT (Ästhetische Theorie), seguida do número de página original, seguido do referente à tradução portuguesa de Artur Morão (cf. bibliografia ao final). Normalmente usamos essa tradução; caso contrário, indicamos entre parênteses. Jan Rosiek, op. cit., p.390-1. 
No início da abordagem sobre o sublime em Adorno, Rosiek faz um apanhado das concepções de Wellmer e de Bohrer, deixando de lado o texto de Welsch, que, segundo ele, não compartilha da ideia diretiva geral do sublime como vinculado à metafísica. Ora, precisamente esse motivo que levou Rosiek a desconsiderar a concepção de Welsch leva-nos a tomá-la como significativa para estudarmos o sublime em Adorno.

Wolfgang Welsch lê toda a filosofia da arte de Adorno como uma "estética implícita do sublime" e analisa a Teoria estética como concebendo a arte essencialmente a partir dessa categoria. Tal interpretação tem sua validade em várias de suas colocações, mas, segundo pensamos, mostra-se equivocada em outras, principalmente no que concerne à sua concepção do conceito de reconciliação em Adorno.

Segundo Welsch, a Teoria estética deve ser lida como um abandono crescente da ideia de reconciliação [Versöhnung] na arte em favor da de justiça [Gerechtigkeit] ao particular, às suas contradições, movimento em que o sublime se mostra como o ponto teórico mais relevante e inequívoco a este respeito. Welsch estabelece então as relações Versöhnung-belo e Gerechtigkeitsublime. O conceito de belo estaria ligado à ideia de reconciliação dos conflitos dos particulares, e o sublime, à de exposição não-conciliada das contradições e antinomias entre eles: o foco da arte passaria então "da reconciliação para a irreconciliabilidade, do nivelamento das contradições para sua articulação, da aparência de salvação [Erlösung] para a evidência do conflito" (Ä̈ 134). Segundo o autor, a ideia de reconciliação na obra de arte deve ser enfraquecida até se tornar apenas uma figura de pensamento, apenas uma maneira (cada vez menos potente) para se pensar a arte na Teoria estética. O belo seria, "segundo toda sua estrutura, apenas um pseudônimo para o sublime" (Ä̈ 122), ou seja, onde Adorno fala da beleza estaria em jogo propriamente este último, que seria, por assim dizer, o que caracteriza mais essencialmente todo o pensamento de Adorno sobre a arte.

Para fundamentar sua posição, Welsch parte da crítica explícita que Adorno faz ao procedimento estético de tomar objetos já considerados sublimes como matéria ou tema [Stoff], caracterizando o que Adorno chama de sublime oco [hohles Erhabenes] (cf. ÄT 294), pois em sua positividade liga-se ideologicamente ao poder, através de sua glorificação imagética (cf. ÄT 224/171). Como início histórico dessa categoria, considerou-se sublime um conceito "bombástico" de espírito, considerado um dominador

9 Wolfgang Welsch. "Adornos Ästhetik: eine implizite Ästhetik des Erhabenen", (doravante referido como AÄ no corpo do texto), pp. 114. 
e opressor da natureza, como Adorno vê em Kant: "a 'grandeza do homem como um espiritual e que oprime a natureza' (ÄT 295) forma o ponto de partida da carreira do sublime" (AÄ 118). Segundo Welsch, Adorno nega essa concepção em favor de sua transformação: "da dominação sobre a natureza para a experiência da própria naturalidade" (idem). Essa passagem seria feita a partir da concepção da natureza como um poder infinito que não pode ser dominado, em que ela é vista não como aquilo que oprime efetivamente, mas que participa em uma libertação da constrição subjetiva. Haveria, assim, um duplo movimento rumo à liberdade: "emancipação do sujeito da obrigação de domínio soberano sobre a natureza", experimentado por ele como um abalo [Erschütterung] de sua subjetividade, "e libertação da natureza da "conexão perversa da naturalidade [Naturwüchsigkeit] e soberania subjetiva' (ÄT 293)" (Ä̈ 120). Tais momentos se ligam aos de desprazer e prazer no sublime, "pois o que o sujeito que pretende subsistir experimenta como desprazer de seu abalo, tal apresenta-se para o saber mais profundo, que acompanha subterraneamente toda a tensão subjetiva, como uma felicidade [Glück], como realização propriamente de sua 'nostalgia' pelo 'que é vetado ao sujeito pelo bloco subjetivo' (ÄT 396)”. (AÄ 121) - Até aqui, temos uma exposição fiel ao texto adorniano, compartilhada por outros intérpretes e que toca realmente em pontos significativos da concepção presente na Teoria estética, mas se refere mais propriamente à interpretação que Adorno faz em relação ao sublime na natureza em Kant. Vejamos então como Welsch interpreta a Teoria estética considerando a arte como sublime.

O esquema geral de tal interpretação é o seguinte: já que o que é experimentado como sublime na natureza é a negação feita por esta sobre a dominação subjetiva sobre ela, a arte é considerada sublime quando recusa a dominação subjetiva precisamente ao negar seu próprio conceito, o qual exige dela uma disposição racional dos particulares na obra, uma vez que estes não aceitam de antemão o que lhes é imposto. Se para a obra se afirmar como arte é necessário o elemento de dominação racional, a arte sublime exerce uma dominação que tende a negar aquele, expondo e articulando as contradições em vez de conciliá-las (o que seria o caso da arte bela). Sem essa negação do elemento de dominação que toda arte tem, a obra apenas afirmaria a perniciosa dominação externa, prática, da natureza. "A arte se completa não em sínteses, mas sim ao rompê-las, mas ela o faz 'com a mesma força' (ÄT 209) que antes as realizava” (A ̈̈ 126). A negação interna da dominação racional na arte é índice da "reprodução da natureza oprimida e entrelaçada na dinâmica histórica" (苂 198, cf. Ä̈ 126), o que já se afigurara como pertencente ao sublime como libertação da natureza do contexto de dominação subjetiva. 
Assim, conclui o autor, "a arte, como a Teoria estética a pretende, realiza a estrutura não do belo, mas do sublime. A estética de Adorno representa tanto em seu coração [Herzen], como em suas leis [Gesetzen], uma estética do sublime" (A ̈ 127).

O restante do texto de Welsch é dedicado a mostrar o enfraquecimento do conceito de reconciliação em favor do de justiça ao particular, em que a arte se mostra como uma reconciliação de contradições radicalmente recusada. A ascendência do sublime na arte seria, nesse movimento, índice da "dissolução do ideal de reconciliação" (AÄ 132). Tal ideal reconciliador teria sido promovido pela estética filosófica, que acolheu em seu interior antes a estética do belo, que se realizou sob a égide da reconciliação (entre o reino da liberdade e da natureza, em Kant, por exemplo), em detrimento da do sublime, que rejeitou tal ideal, pois "articulou contraposições, rupturas e momentos de conflito que resistiam a uma última integração" (A ̈̈ 138).

Ao fazermos uma análise da interpretação de Welsch, o primeiro ponto que nos parece problemático é justamente a tese central de que a reconciliação em Adorno somente deve ser tomada como válida na medida em que se enfraquece para dar lugar à ideia de justiça ao particular, em que o ideal reconciliatório cede sua vez à articulação das contradições. Percebemos aí uma unilateralidade do conceito de reconciliação. Welsch toma esta noção como vinculada quase exclusivamente à ideia de resolução de antagonismos, de fim das contradições. É claro que esse significado é pertinente para aquele conceito, sendo isso visível em várias passagens dos textos adornianos, mas sua exclusividade abstrai algo mais difícil de perceber no pensamento de Adorno, que é a ideia de que a reconciliação significa a consciência da distinção entre sujeito e objeto. Trata-se, não de uma harmonia pacificada, de uma resolução de tensões, de um nivelamento de conflitos, mas sim de relações de alteridade e diferença em que o não-idêntico nas coisas e no sujeito se exprima sem pagar o preço da pura dispersão sem sentido ou do aprisionamento na mediação falsificadora do universal. Por outro lado, mesmo tomando-se apenas o primeiro sentido para o conceito de reconciliação, a ideia de Welsch mostra-se inadequada. Como muito bem apontou Klaus Baum, as noções de utopia e de reconciliação, estreitamente ligadas em Adorno, recebem na Teoria estética a determinação de que elas incluem necessariamente em si a negação do que elas prometem, ou seja, na própria ideia de reconciliação o seu não-cumprimento é signo de sua verdade ${ }^{10}$. O que parece escapar a 
Welsch é que a recusa da efetividade da reconciliação na arte não acontece em favor da justiça ao particular (que se lhe oporia) e em detrimento da própria ideia de reconciliação, mas sim em favor dela, ou seja, a reconciliação no âmbito estético contém em si a cláusula de sua insuficiência como atualidade. Embora outras passagens de textos de Adorno autorizem uma leitura mais positivada da reconciliação, como o último ensaio das Minima moralia, o que nos parece mais significativo como interpretação de sua estética é a ideia de que a impossibilidade de marcar um espaço de identidade e diferença entre sujeito e objeto de forma conceitualmente estrita qualifica propriamente a reconciliação como um ponto de fuga e um modo de seu vislumbre através do âmbito imagético da arte. O que funda a possibilidade de a justiça ao particular, em sua articulação de contradições e conflitos, ser verdadeira, é que ela se dá no interior de um movimento de expressão não-violenta de diferenças, tensões e alteridades na obra de arte, ou seja, ela somente existe enquanto verdade em relação aos próprios particulares porque aponta para a possibilidade de superação da violência a que se submete a particularidade. ${ }^{11}$

Uma vez colocada essa primeira crítica, parece-nos claro que as relações que Welsch estabelece tão nitidamente para belo-reconciliação e sublimejustiça ao particular se mostram problemáticas. Cremos que elas tenham maior validade em relação às suas análises referentes às estéticas anteriores a Adorno, mas, frente a este, elas são equivocadas, e isso de modo mais claro se consideramos que o conceito de reconciliação inclui a ideia-mestra de uma primazia do objeto, de uma quebra do encantamento que o sujeito lança sobre o objeto e sobre si mesmo, de tal modo a se perceber, na distância mediada entre ambos, o espaço que pode configurar o solo da liberdade. De nosso ponto de vista, a justiça às contradições do particular exprime, no âmbito das reflexões estéticas de Adorno, virtualmente a mesma coisa contida na ideia de reconciliação. Um apoio que nos parece importante para essa perspectiva é uma passagem do texto "Rede über Lyrik und Gesellschaft", em que Adorno diz das grandes obras de arte "que sua essência consiste em dar forma às contradições na existência real, e somente nesse sentido, [consiste] em uma tendencial reconciliação delas" [die an Gestaltung und allein dadurch an tendenzieller Versöhnung tragender Widersprüche des realen Daseins ihr Wesen haben ${ }^{12}$.

11 Embora use uma argumentação diferente da nossa, A. Wellmer também discorda de Welsch nesse ponto: "Em contraste com Welsch, (...) não creio que a categoria do sublime signifique uma corrente da filosofia de Adorno que se oponha a sua filosofia da reconciliação; creio, antes, que ela ocupe um lugar central dentro de sua estética de reconciliação: sua estética, como uma estética de reconciliação, é, ao mesmo tempo, uma estética do sublime" (op. cit., p.115).

12 "Rede über Lyrik und Gesellschaft", p.51. 
A unilateralidade do ponto de vista de Welsch pode ser esclarecida a partir da crítica que Rosiek lhe fez, ou seja, que ele estaria interessado em aproximar a concepção adorniana do sublime à de Lyotard, tomado por Welsch como expoente e fundador da filosofia pós-moderna. ${ }^{13}$

O ponto forte da concepção de Welsch, entretanto, é sua ênfase na dimensão constitutiva da experiência estética como conflituosa, contraditória, não apelando para estruturas situadas em outras esferas (como a da comunicação ou da teologia) a fim de "apreender" o significado dessas contradições. Mesmo nessa "vantagem", porém, sua concepção tem uma fraqueza, pois, embora a subjugação do movimento de negatividade da arte por um âmbito extra-estético para sua apreensão de sentido não nos pareça válido, algo deve ser pensado como se situando nesse ponto. Aqui podemos invocar a ideia de Thomas Weiskel de que o sublime intra-humano é algo contraditório: "sem noção alguma do além, ou discurso plausível do sobre-humano, o sublime soçobra ou torna-se um 'problema'. Isso é verdadeiro tanto para o Romantismo quanto para a Antiguidade. Diz Schiller: 'o belo é valioso apenas em relação ao ser humano, mas o sublime o é em relação ao puro demônio [dämon]' no homem, 'aos estatutos do espírito puro'. Um sublime humanístico é um oximoro" 14 . Nós diríamos que a história da filosofia tornou-o um oximoro, afunilando a noção de alteridade, tal como se afigura no sublime, para a de infinitude (de grandeza e de força), o que favoreceu a consideração de Kant de que somente a natureza (e em seu aspecto disforme, bruto) é capaz de suscitar o sentimento de sublimidade. Nossa intenção é a de mostrar como a transcendência na arte pode ser pensada em íntima associação com o que lhe é imanente, interno. A dimensão histórica conteria tal "ambivalência", de modo a poder ser apreendida nesse movimento pendular entre uma determinação intrínseca e outra que ultrapassa o confinamento monadológico de cada obra.

\section{II}

É preciso ver, inicialmente, o que Adorno concebe como uma falsa concepção da historicidade artística: "O contrário de uma genuína relação com

13 Cf. Jan Rosiek, op. cit., p.345, nota 1. - Mas, por falar em unilateralidade, vemos que tanto Wellmer quanto Rosiek também padecem desse mal. O primeiro procura ler Adorno sob o parâmetro da racionalidade comunicativa de Habermas, e o último, a partir da perspectiva teológico-metafísica.

14 Thomas Weiskel. O sublime romântico. Estudos sobre a estrutura e psicologia da transcendência. p.17. Ao analisar o sublime kantiano, Lyotard também levanta uma questão afim a esse posicionamento: “(...) é possível, e como, testemunhar o absoluto por meio de representações artísticas e literárias, que são sempre submetidas a formas?", Lições sobre a Analítica do Sublime, p.144. 
o elemento histórico das obras como seu próprio conteúdo é a sua apressada subsunção na história, sua remissão ao lugar histórico" (ÄT 290/220; tradução própria). Essa tomada de posição condenada pelo autor da Teoria estética é o que ele chama de historicismo [Historismus]. Ela consiste nessa subsunção da obra na história enquanto um dos elementos de uma sequência que se desdobra temporalmente. De acordo com essa concepção, a arte seria histórica porque faria parte de um continuum histórico que unifica e dá sentido a todos os seus integrantes. Podemos interpretar o qualificativo "apressada" [eilfertige] para o ato dessa subsunção como a eliminação de uma série de mediações - tanto teóricas quanto na experiência com as obras - que devem ser levadas em conta para se apreender o caráter histórico da obra de arte. Sem tais mediações, a história se apresenta para a arte como um destino exterior (cf. ÄT 285/217), ou seja, como algo que englobaria o que há de legítimo na sequência das manifestações estéticas. Dado que no historicismo há, como na concepção hegeliana da história, um desdobramento de um sentido que subjaz aos acontecimentos, ou remetemos a obra de arte para a sequência histórica em seu todo, ou então ela não vale nada por si como verdade acerca do espírito ${ }^{15}$, ou seja, perde sua legitimidade em si mesma.

Contra essa concepção historicista, a historicidade da arte é tomada como imanente a ela, como um caráter processual [Prozeßcharakter] constitutivo da identidade da obra como arte: "A obra de arte é processo essencialmente na relação do todo e das partes. Não podendo reduzir-se nem a um nem a outro momento, essa relação é, por sua parte, um devir" (ÄT 266/202; tradução própria). A impossibilidade de a arte manter-se enquanto tal optando ou pela totalidade fechada de seus momentos, ou pela dispersão absoluta de suas partes obriga-a a buscar um equilíbrio instável, que não se resolve em definitivo para nenhum dos dois polos. Os antagonismos reinantes entre as particularidades dos elementos introduzem um fator de destruição e morte no núcleo da arte que tende a desfazer a sua própria identidade. A ânsia mítica pela sobrevivência para além do desconhecido, entretanto, herdada das origens mágicas da arte, leva-a a separar-se da empiria multiforme e dispersa através da colocação de uma esfera idêntica a si mesma, no "reino autóctone do espírito", mas que precisa, para conservar tal auto-identidade, do seu "nãoidêntico, heterogêneo, não-ainda-formado" (ÄT 263/200). Por isso Adorno diz que o próprio conceito de "equilíbrio" para definir esse estado se contradiz

15 "Se não se sabe nada dessa [a verdade eterna do espírito - vf], então não se sabe nada de Verdadeiro, Justo ou Ético". Georg W. F. Hegel. Vorlesungen über die Philosophie der Weltgeschichte. Vol. I: Die Vernunft in der Geschichte, p. 45. 
a si mesmo (cf. ÄT 266/202). Mas tal posição exige certa totalidade, pois, sem ela, como falar de uma "obra", um ser, um algo que efetivamente existe? O resultado, portanto, é, paradoxalmente, um equilíbrio em devir:

Se a obra de arte não é em si nada fixo, definitivo, mas sim algo móvel, então sua temporalidade imanente se comunica às partes e ao todo no fato de que a relação destes se desdobra no tempo, e de que eles podem denunciá-la. Se as obras de arte vivem, graças a seu caráter processual, na história, então elas podem se perder nela. (ÄT 266/202; tradução própria)

A dinâmica da obra de arte é precisamente essa irresolução entre o aspecto disperso, de multiplicidade, de alteridade, em relação ao espírito, e a necessidade de a obra se constituir como algo idêntico a si, como algo espiritual, fabricado, que, portanto, precisa encerrar-se em um todo. Sem poder inclinar-se definitivamente para nenhum dos dois polos, sob pena de se perder em meio à mera contingência sem pretensão a voz, ou igualar-se à violência do universal abstrato, a única chance de a arte prosseguir na história é expor seu "núcleo temporal", o que a torna, por outro lado, frágil, diante da necessidade reinante de uma universalidade afirmativa no sistema de autoconservação individual e coletivo.

Se, entretanto, o sentido da obra é referido por Adorno à construção de sua unidade (cf. ÄT 229-235/175-179), e se tal unidade não é o ponto definitivo por meio de que a obra alcança a duração, mas em um equilíbrio insatisfeito entre os antagonismos dos particulares e a totalidade formal, a consecução e o alcance de um sentido para a própria arte seria a anulação de si mesmo. Assim, "seja o que for que no artefato se pode chamar a unidade de seu sentido não é estático, mas sim processual (...)” (ÄT 262/200; tradução própria), ou seja, o sentido da própria arte não é algo dado de antemão, nem possível de ser alcançado em definitivo através de seu desdobramento historiográfico. Adorno faz um jogo com a polissemia da palavra "processo", dizendo que "é objetivo o caráter de processo imanente das obras de arte - mesmo antes que elas assumam um partido qualquer -, o processo que elas promovem contra o que lhes é exterior, o mero subsistente" (ÄT 264/201). A palavra ganha uma conotação jurídica, em que a radical separação da obra de arte em relação à existência reificada exterior procura fazer justiça ao que é recalcado na realidade empírica, mostrando a esse "que ele mesmo deve ser de outro modo: esquema a-consciente de sua modificação" (idem).

Esse caráter processual, histórico, das obras, traduzido em termos das relações entre o todo e as partes, é transposto porAdorno também para o conjunto das obras: "Imanentemente dinâmicas, entretanto, são não apenas as obras de 
arte individuais, mas também sua relação recíproca" (ÄT 263/200; tradução própria). Ora, se a dinâmica das obras se faz nas relações de antagonismo entre os particulares, que, assim, "não se encontram em justaposição, mas atritam-se ou atraem-se mutuamente, um querendo ou repelindo o outro" (ÄT 275/209; tradução própria), e se essa dinâmica está presente na esfera das relações entre as obras, então se nos afigura incompreensível como Adorno pode dizer, em sequência à primeira citação deste parágrafo, que "a relação da arte é histórica, entretanto, somente através das obras individuais, imóveis em si, não através de sua relação exterior, ou mesmo através da influência que elas devem exercer uma sobre a outra" (ÄT 263/200; tradução própria, grifos nossos). Ora, como seria possível perceber uma dinâmica, um caráter histórico, processual, portanto, em que haja atrito, repulsão e atração, sem que os elementos em jogo - no caso as obras individuais - exerçam influência uma sobre a outra, sem que isso contribua na constituição da identidade de cada obra? Em outras palavras: o que significaria dizer que as relações entre as obras individuais tenham também uma dinâmica imanente $e$ que tais relações não contribuam para o caráter histórico, ou seja, de uma dinâmica imanente, para a arte? - e, além disso, que as influências recíprocas das obras também não contribuam para a dinamicidade de cada uma delas? - Esse impasse, para o qual não vemos solução dentro da argumentação de Adorno no âmbito argumentativo em que é colocado, será útil, entretanto, para nossa hipótese interpretativa, e voltaremos a ele mais à frente.

Embora seja "problemático" o estabelecimento das relações entre as obras particulares como históricas, processuais, por outro lado é inequívoco que Adorno considera esse caráter processual como algo objetivo, ou seja, não se trata de um desdobramento temporal tomado apenas do ponto de vista da recepção (cf. ÄT 266/203). Que as obras de arte se modifiquem é devido à sua lei formal, ou seja, essa modificação tem seu fundamentum in re, é uma característica objetiva delas, de forma alguma acontece somente de acordo com a recepção que se tem delas em cada época histórica. Que as obras estejam na história isso é devido ao caráter de devir gerado pelas tensões internas da obra, na relação do campo de forças antagônico entre sua totalidade e as contradições reinantes no seio das particularidades. Ora, tais relações constituem a própria lei formal da obra.

Temos em Adorno, porém, várias outras considerações acerca desse caráter de objetividade, e, assim, de universalidade. Ele é tomado em conta também pelo lado da recepção, por exemplo, da qual "não se deve abstrair esquematicamente" (ÄT 288/219; tradução própria). Embora as obras de arte tenham uma parcela da vontade mítica de sobrevivência espelhada em sua 
“fixação na pedra, na tela, no texto literário ou de notas musicais", elas não escapam da modificação temporal, pois "o fixado é signo, função, não em si; o processo entre ele e o espírito é a história da obra" (idem - grifos nossos). Aqui entra em jogo uma dimensão nova: a historicidade da obra se dá entre ela e o espírito, o que significa que a lei formal da obra, isto é, aquilo que determina seu caráter processual, é por sua vez determinada também pela recepção, pela crítica, pela interpretação que se faz dela: "se as obras de arte acabadas tornam-se o que elas são porque seu ser é um devir, então elas são por seu turno remetidas a formas em que aquele processo se cristaliza: interpretação, comentário e crítica" (ÄT 289/220; tradução própria). Se o ponto de equilíbrio instável que caracteriza as obras como um devir (seu núcleo temporal) não reside nem no seio da particularidade por si só, nem na unidade de todos os seus momentos, mas em um lugar a rigor inconceituável, então, de forma semelhante, esse mesmo caráter histórico/processual das obras não se situa nem na própria obra, nem na soma das formas de sua recepção, mas entre esses dois planos. Tais formas de recepção não são, assim, elementos exteriores ao que constitui a própria identidade (histórica) da obra, mas são "o palco do movimento histórico das obras em si e por isso formas por direito próprio. Elas se prestam ao conteúdo de verdade das obras como a algo que as ultrapassa e separam-no - a tarefa da crítica - dos momentos de sua inverdade. Que o desdobramento das obras seja bem sucedido, para isso aquelas formas de recepção devem agudizar-se até a filosofia" (idem).

\section{III}

Essa vinculação entre a historicidade da arte e a filosofia pode, enfim, ser pensada diretamente em relação ao sublime. Segundo Adorno, "o sublime, que Kant reservou à natureza, tornou-se após ele um constituinte histórico da própria arte" (ÄT 293/222-3; tradução própria). Isso significa que a grande arte subjetiva burguesa absorveu tudo aquilo que a natureza prometia como sublime, ou seja, como expressão de um absolutamente outro, de uma liberdade do âmbito das relações concretas de produção. Isso é o que se deu na arte com a antinomia, fundadora da arte moderna, da necessidade de produzir sua própria transcendência, sem poder situar-se para além dos limites do artefato humano, nem desistir da persecução desse ideal de transcendência. Mas a interpretação que fazemos do vínculo entre tal transcendência secularizada e a historicidade na arte permite-nos, por outro lado, fazer uma paráfrase da ideia de Adorno citada acima, dizendo que, na arte a história tornou-se um constituinte do próprio sublime. 
Como é bem conhecido, ao definir o sublime na natureza, Kant dividiu-o em dois momentos: o matematicamente-sublime [MathematischErhabene], que diz respeito à natureza em sua infinidade de grandeza física, e o dinamicamente-sublime [Dynamisch-Erhabene], que se relaciona à incomensurabilidade da força física das potências naturais. Schiller rebatizouos como teoricamente-sublime e praticamente-sublime. ${ }^{16}$ De acordo com os conceitos que usamos para circunscrever a arte moderna como sublime, dizemos que ela é historicamente-sublime. Apesar do vínculo aparente que essa denominação tem com a concepção kantiana, há uma diferença fundamental. Em Kant, os advérbios que antecedem o termo "sublime" dizem respeito ao que provoca o sentimento em jogo, ou seja, as infinidades de grandeza e de força naturais. Em nossa definição, o advérbio "historicamente" vincula-se mais propriamente ao sentido da experiência de contato com a obra, embora também se ligue a seu fundamento.

Dois momentos da Teoria estética apóiam essa aposta interpretativa. O primeiro diz respeito à transcendência estética: "as obras em que a forma estética se transcende sob a pressão do conteúdo de verdade ocupam o lugar que outrora o conceito de sublime significava" (ÄT 292/222 - grifos nossos). A arte pratica uma secularização da transcendência, na medida em que torna objetivo o que é radicalmente outro perante a realidade empírica. A arte duplica imageticamente o estremecimento [Erschütterung] diante do que sempre se mostrou incomensurável aos homens, o Mana, o poder difuso da natureza. $\mathrm{O}$ deslocamento aprofundado do núcleo ontológico do cosmo em um ponto originário da criação no mito, a fluidez do poder infinito e amorfamente disperso pelos poderes naturais no pré-animismo e na magia são aquilo que empresta à alteridade radical da natureza sua evanescência suprema. A arte é um momento que procura conjurar essa efemeridade ao se pôr como sua cópia objetivadora: prolongamento do transitório no artefato. A arte produz uma mediação imagética que dá voz ao que transcende de forma difusa a circunscrição das coisas como simples objetos, ao mesmo tempo em que retira da transcendência a ilusão de ser literal, por confiná-la em uma totalidade que se assume como mera aparência.

O segundo momento de apoio a nossa hipótese se dá na relação íntima que Adorno estabelece entre conteúdo de verdade e historicidade na arte: "a história pode se chamar o conteúdo das obras de arte" (ÄT 132/103); "analisar as obras artísticas equivale a perceber a história imanente nelas armazenada" alheio. Cf. "Vom Erhabenen", pp.489-512. 
(ÄT 132/103); "o conteúdo de verdade das obras de arte, do qual sua qualidade depende finalmente, é histórico até o mais profundo de si mesmo" (ÄT 285/217); também é significativa uma colocação nuclear de Adorno sobre o vínculo entre sociedade e a forma estética: "Os antagonismos não resolvidos da realidade retornam às obras de arte como os problemas imanentes da sua forma" (ÄT 16/16). Embora provavelmente poucos comentadores de Adorno se sintam à vontade para empregar argumentos interpretativos baseados em silogismos, parece-nos mais do que legítimo dizer, associando a primeira passagem acima a estas últimas, que a auto-transcendência da forma estética se dá precisamente em virtude do modo como a história que se sedimenta esteticamente impele, constrange, à ultrapassagem das vicissitudes próprias do confinamento monadológico de cada obra. A história mostra-se como um plano de alteridade cuja força é significativa para fazer com que a arte, em seu poder de mediação imagética, afirme-se em sua essencial diferença perante a realidade empírica.

Seria difícil exagerar o quanto a distinção arte-empiria é significativa para toda a estética de Adorno. Christopher Menke a exprime de forma exemplar: "as obras de arte somente podem ser apreendidas em sua autonomia, na lógica própria de sua apresentação e experiência, por quem as concebe em sua relação negativa perante tudo o que não é arte" ${ }^{17}$. Como, por outro lado, é igualmente importante enfatizar o modo como a historicidade extraestética ainda permanece na arte - "a arte é a antítese social da sociedade"

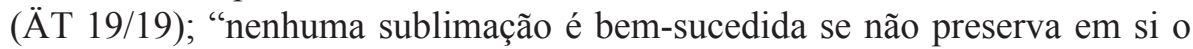
que foi sublimado" (ÄT 145/113) -, muito do sentido da leitura adorniana do fenômeno estético consistirá em mostrar que a arte somente faz sentido através de uma articulação absolutamente rigorosa de seus elementos particulares, suficientemente capaz de produzir uma refração (e não um aniquilamento) do significado que eles possuem na realidade empírica. Esta quebra, esta ruptura, que Adorno associa ao conceito psicanalítico de sublimação, constitui precisamente o momento de liberdade das obras perante o fluxo histórico e da realidade sócio-empírica (cf. ÄT 33/29 e 196/151). Para nossos fins, importa salientar o quanto este processo de metabolização do extra-estético lhe confere o caráter "explosivo", de uma força que impele à transcendência da forma da obra. A historicidade imanente da arte seria fruto de um modo sui generis com que a arte é capaz de articular as tensões contraditórias na realidade empírica, tornando eloquente aquilo que escapa à racionalidade que conforma nosso 
olhar para o real em sua dimensão primeira. Embora não tenhamos aqui espaço suficiente para desenvolver a temática, temos nessa articulação conceitual um modo de compreender a importante noção adorniana de "linguagem do sofrimento", na medida em que este último é tomado como a experiência, o impacto e o significado subjetivos de uma série de conflitos e contradições que incidem sobre o indivíduo nas diversas formas com que o universal coletivo pesa sobre ele. Nessa medida, o sofrimento, sem sua articulação rigorosamente estética, permanece mudo, ou seja, incompreensível em sua racionalidade própria, sendo vivenciado de forma caótica, imobilista e angustiada nas diversas espécies de neurose. - Em suma, segundo nossa leitura, a alteridade substantiva da realidade empírica perante a arte é assimilada de forma estética na medida em que, ao sofrer uma refração essencial, adquire um poder de compelir à transcendência da obra por si mesma. Em vez de ser apenas um destino exterior, a história nutre a arte intrinsecamente de um conteúdo que a impele radicalmente a ir além de uma mera configuração empírica de elementos materiais. Ao conferir uma eloquência ao que permanece recalcado na realidade exterior, essa transcendência estética aponta enigmaticamente para um espaço de liberdade reflexiva.

Tal caracterização, entretanto, não é isenta de certa problematicidade em seu apoio na Teoria estética. Segundo Adorno, a categoria do sublime é aplicável à arte como um todo, e não a cada obra particular. Em dois momentos ele afirma isso:

Dever-se-ia contrapor ao hedonismo estético aquela passagem da teoria kantiana do sublime, que ele, timidamente, recusa à arte: a felicidade nas obras de arte seria, quando muito, o sentimento da resistência, que elas medeiam. Isso vale antes para o domínio estético como um todo do que para a obra de arte individual. (ÄT 31/27; tradução própria)

Frente a obras de arte concretas não se deveria falar mais do sublime sem a ladainha da religião cultural, e isso é derivado da dinâmica da própria categoria. (ÄT 295/224)

O sublime em relação a cada obra singular, portanto, somente poderia ser considerado como oco, vazio, já salientado por Welsch, em que a sublimidade reside em procedimentos e temas de antemão considerados grandiosos, pomposos, e que, com justa razão, são rechaçados por Adorno.

A ideia de que o domínio estético como um todo, historicamente considerado, reserve um lugar para o sublime na arte nos parece correta, mas que esse lugar somente exista se se considera a totalidade desse domínio, tal concepção se apresenta incompatível com a ideia de que "obras em que a forma estética se transcende, sob a pressão do conteúdo de verdade, ocupam o lugar que outrora o conceito de sublime significava". Com efeito, se se pode 
perceber que há essa autotranscendência da forma nessas obras, por que não se poderia falar delas adequadamente segundo a categoria do sublime? Por que a interpretação filosófica não seria capaz de perceber, em cada uma dessas obras em que a forma se transcende, o seu caráter de sublimidade? - Aqui devemos voltar àquele impasse de que falamos anteriormente, em que Adorno insistiu, de forma paradoxal, em dizer que a relação temporal das obras de arte somente se dá na singularidade de cada uma, e não na relação entre elas, pois agora vemos algo também difícil de assimilar, mas que se encaminha para o outro extremo, considerando a sublimidade apenas no âmbito macro, da história da arte em sua totalidade. Isso aponta, segundo pensamos, para uma tensão inerente ao pensamento adorniano, no que concerne ao significado da relação singular com uma obra e aquele resultante do vínculo entre as obras particulares, e delas com todo o movimento histórico. Não vemos aí, todavia, um índice de fraqueza de sua concepção, mas sim de uma verdade relativa à própria experiência estética, a saber, da impossibilidade de fixar uma identidade e diferença nítidas entre o que constitui a arte a partir de um movimento histórico geral e cada obra na medida em que é bem realizada.

De forma análoga a como o sublime kantiano é interpretado por Adorno como testemunho da possibilidade de uma liberdade perante aquilo que reside no próprio sujeito como um princípio de coerção da identidade, de modo que a objetividade do objeto se exprime no questionamento dos princípios de conformação subjetiva, a arte se mostra sublime na medida em que tenciona os fios que tecem sua identidade e sua diferença em relação ao movimento macro de constituição do âmbito estético. Tal como a identidade de cada obra não é dita como definitiva, mas sim eivada das questões que permeiam a história dos comentários, das críticas e das interpretações, o caráter artístico, por depender da sedimentação histórica de conteúdos sociais na forma estética, se firma e é colocado em xeque nessa relação tensa em que "cada obra é a inimiga mortal da outra" (ÄT 59/49). A impossibilidade de fixação da identidade e da diferença no conceito que se tenha da arte, ao mesmo tempo em que questiona a fixação de seu sentido, demonstra o quanto este surge pelas sucessivas instaurações particulares de sentido, que, como salientou Welsch, é contrariado por cada uma delas. Se a forma é a síntese não violenta do disperso - pois a particularidade ganha sua eloquência pelo modo como é acolhida em uma totalidade que somente se firma ao aglutinar cada um de seus elementos constitutivos e mantê-los em sua diferença -, então cada obra de arte particular deverá se inserir em um movimento histórico em que essa totalidade sedimentada processualmente se nutre das vicissitudes com que cada obra se mostra refratária a esta acomodação. 
$\mathrm{Na}$ busca por uma alteridade cuja diferenciação não signifique uma positividade do que é (totalmente) outro em relação ao sujeito, o plano histórico, tomado como um movimento de conjugação de forças que ultrapassam a perspectiva individual, é concebido por Adorno, tal como dissemos, não como etapas sucessivas de auto-reconhecimento de um Absoluto que se desdobra através delas, como na filosofia hegeliana. Ao mesmo tempo, não é tomado como a soma dos processos e eventos que se concatenam empiricamente. Tratase de uma objetividade social cuja unidade se constitui proporcionalmente ao modo com que as diferenças entre os eventos particulares a ratificam e a contrariam. Na medida em que a história "oficial", vivida de forma ao mesmo tempo consciente e ideológica pela mediação dos discursos e saberes, demonstra a sedimentação de relações de poder que recalcam ímpetos miméticos, próximos a planos mais arcaicos de nossos desejos e sentimentos, as obras de arte apresentam-se como testemunhos cifrados e enigmáticos deste estrato subterrâneo da história. A arte não expõe uma verdade do particular em sua singularidade, mas sim exprime, de forma radicalmente mediada pela configuração da imagem estética, o quanto o singular alcança certa inteligibilidade perante sua mescla indissolúvel com aquele substrato historicamente constituído. Deste modo, o caráter processual das obras de arte passa por, mas ultrapassa, a necessidade de interpretação contextualizada, de uma leitura historicamente informada, pois ele significa o quanto o sentido propriamente estético da relação com a obra de arte implica o que chamamos de relação mimética com o tempo histórico. $\mathrm{Na}$ demanda de exegese de uma obra cujo instante não apenas espelha o movimento da história, mas o evoca naquilo que ultrapassa o olhar racionalizado e dirigido à sua superfície, tem-se que a relação de identidade e diferença, de semelhança e contraste elementos próprios da mímesis -, mostra o quanto a arte somente subsiste como uma experiência-limite do que transcende o instante pelo modo como aglutina enigmaticamente um sentido coletivo e ao mesmo tempo individual. Dessa não-resolução se nutre o caráter enigmático da arte, que não se perde no abismo de um mistério religioso/teológico/místico, nem tampouco se resigna a espelhar imageticamente a sedimentação empírica do movimento históricosocial na realidade das coisas, dos desejos, dos valores sociais etc.

A historicidade imanente ao estético mostra-se como o palco em que o movimento de auto-transcendência da arte exprime as contradições, diferenças e conflitos não-resolvidos da realidade exterior - tal como salienta parte da tradição de comentários sobre este tópico em Adorno -, como também permite conceber um plano de significação que ultrapassa as vicissitudes ligadas à singularidade monadológica de cada obra, sem que isso implique o recurso a 
instâncias metafísico-teológicas (tal como apontamos na leitura de Jan Rosiek) ou conceitos de intersubjetividade comunicativa (como vemos na perspectiva de Albrecht Wellmer), ao mesmo tempo em que nos permite ir além de uma interpretação por assim dizer nietzschiana da estética de Adorno $^{18}$ (ao modo como Wolfgang Welsch concebe), que faz da exposição das contradições, do caos e da negatividade dos particulares a caracterização do sublime em sua significação total. Em virtude desta forma sui generis de enfrentamento e de assimilação imagética do tempo histórico dizemos, então, que a arte moderna seria historicamente-sublime.

\section{Referências bibliográficas}

ADORNO, Theodor Wiesengrund - Ästhetische Theorie. Gesammelte Schriften, vol.7. Frankfurt: Suhrkamp, 1997.

- Negative Dialektik. Gesammelte Schriften, vol.6. Frankfurt am Main: Suhrkamp, 1997.

- Philosophie der Neuen Musik. Gesammelte Schriften, vol.12. Frankfurt am Main: Suhrkamp, 1997.

- "Rede über Lyrik und Gesellschaft". In: Noten zur Literatur. Gesammelte Schriften, vol. 11, Frankfurt am Main: Suhrkamp, 1997, pp.49-67.

- Teoria Estética. Tradução de A. Morão. Lisboa: Martins Fontes, 1982.

ADORNO, Theodor Wiesengrund \& HORKHEIMER, Max - Dialética do esclarescimento. Tradução de Guido Antônio de Almeida. Rio de Janeiro: Jorge Zahar Editor, 2006.

BAUM, Klaus - Die Tranzendierung des Mythos. Zur Philosophie und Ästhetik Schellings und Adornos. Würzburg: 1988.

DUARTE, Rodrigo A. P. - "Expressão como fundamentação". In: Kriterion. Revista de Filosofia. Volume XXXV, número 91. Belo Horizonte: Departamento de Filosofia da Faculdade de Filosofia e Ciências Humanas, 1995, pp.45-66.

FREITAS, Verlaine Freitas - Para uma dialética da alteridade. A constituição do sujeito, da razão e do tempo em Theodor Adorno. Tese. Belo Horizonte: 2001. Inédito. - Adorno e a arte contemporânea. Rio de Janeiro: Zahar, 2003.

HEGEL, Georg W. F. - Vorlesungen über die Philosophie der Weltgeschichte. Vol. I: Die Vernunft in der Geschichte. Hamburg: Felix Meiner, 1970.

KANT, Immanuel - Kritik der Urteilskraft. Darmstadt: Wissenschaftliche Buchgesellschaft Darmstadt, 1982.

LYOTARD, Jean-François - Lições sobre a Analítica do Sublime. Tradução de Constança Marcondes Cesar. São Paulo: Papirus, 1993. 
MENKE, Christoph - Die Souveränität der Kunst. Ästhetische Erfahrung nach Adorno und Derrida. Frankfurt am Main: Suhrkamp, 1991.

PEÑA AGUADO, María Isabel - "Theodor W. Adorno. Die Transformation des Erhabenen in der Ästhetischen Theorie”. In: Ästhetik des Erhabenen. Wien: PassagenVerlag, 1994, pp.73-90.

ROSIEK, Jan - Mantaining the sublime. Heidegger and Adorno. Berna: Peter Lang, 2000.

SCHILLER, Friedrich - "Über das Erhabene”. In: Sämtliche Werke. München: Carl Hanser, 1989, p.792-808.

SEEL, Martin - "Dialektik des Erhabenen. Kommentare zur 'ästhetischen Barberei heute"'. In: Willem van Reijen \& Gunzelin S. Noerr. Verizig Jahre Flaschenpost: "Dialektik der Aufklärung” 1947 bis 1987. Frankfurt a. M.: Fischer, 1987, pp.11-40. WEISKEL, Thomas - O sublime romântico. Estudos sobre a estrutura e psicologia da transcendência. Tradução de Patrícia Flores da Cunha. Rio de Janeiro: Imago, 1994 WELLMER, Allbrecht - "Adorno, Modernity, and the Sublime". In: Max Pensky (edt.). The Actuality of Adorno. Critical Essays on Adorno and the Postmodern. New York: State of New York Press, 1997, pp.112-134.

WELSCH, Wolfgang - "Adornos Ästhetik: eine implizite Ästhetik des Erhabenen”. In: Ästhetisches Denken. Stuttgart: Reclam, 1993, pp.114-156.

ZENCK, Martin - Kunst als begrifflose Erkenntnis: Zum Kunstbegriff der ästhetischen Theorie Theodor W. Adornos. München: Wilhelm Fink, 1977.

ZUIDERVAART, Lambert - Adorno's Aesthetik Theory. The Redemption of Ilusion. Cambridge: MIT Press, 1991. 